Rapid Reviews COVID-19

\title{
Reviews of "Supporting Families to Protect Child Health: Parenting Quality and Household Needs During the COVID-19 Pandemic"
}

Anne Shaffer ${ }^{1}$, Kathleen McGoron ${ }^{2}$

${ }^{1}$ University of Georgia, ${ }^{2}$ Assistant Professor (Research), Wayne State University

Published on: Oct 11, 2020

DOI: 10.1162/2e3983f5.e0012a69

License: Creative Commons Attribution 4.0 International License (CC-BY 4.0). 
To read the original manuscript, click the link above.

Summary of Reviews: This study presents a generally reliable analysis of data on the effects of stressors on parenting practices during the pandemic, however, inherent limitations of the study design and the need for more detail may undermine its generalizability.

\section{Reviewer 1 (Anne Shaffer)}

\section{Reviewer 2 (Kathleen McGoron)}

$$
\begin{aligned}
& \text { RR:C19 Strength of Evidence Scale Key } \\
& \text { प्रमप = Misleading } \\
& \text { प्र००० = Not Informative } \\
& \text { प्रा पि = Potentially Informative }
\end{aligned}
$$

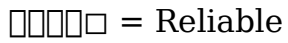

$$
\begin{aligned}
& \text { प्राप्र = Strong }
\end{aligned}
$$

To read the reviews, click the links below. 